\title{
The Challenge of Change: reducing conflict in implementing e-learning
}

\author{
Rosa Michaelson \\ Fellow in Business Computing, Accountancy \& Business Finance \\ University of Dundee, Dundee DD1 4HN \\ Scotland \\ r.michaelson@dundee.ac.uk
}

\begin{abstract}
This paper calls for the design of the European Grid for Learning to take note of important issues which have arisen in previous e-learning cycles in the UK. In particular, low take-up of products and services by lecturers has been explained in terms of techno-fear, or ignorance of e-learning potential. These claims are unsubstantiated. Other explanations are possible for the observed resistance of the educational specialist to the use of educational technology. Rather than ignore possible areas of conflict, or to assume (after Foucault) that any change results in shifts of power which produce inevitable counter-balances from a threatened group, it is possible to use resistance to change as an important part of the design process. To this end, I discuss the findings of an analysis of recent UK-wide initiatives in C\&IT and e-learning. The issues raised by participants of the many different groups involved have implications for the take-up of future Grid-based learning. In particular, the needs of educators are identified as crucial to the effective deployment of e-learning. Keywords: e-learning; design focus for Grid technologies; teacher's rights; Information Systems methodologies; managing change.
\end{abstract}

\section{BACKGROUND}

In the UK Higher Education sector online learning has been greeted with enthusiasm by many. For example, the UK-wide e-University has been launched to meet a suggested lack in HE online provision for lifelong learning [1]. The growth of the virtual university, such as the global conglomerates Fathom and Cardean University, based on Unext.com, has been perceived as a threat to standard university education [2], [3]. Many such ambitious e-learning projects have failed [4].

Evaluation of large Information Systems implementation, and in particular of IS failure, leads to the understanding of the importance of counter-implementation and resistance to change, informing methods which reduce conflict and improve design processes [5], [6]. In order to inform the effective design of a European Grid for Learning we need to consider possible problem areas which might be of concern to the lectures and teachers who will use Gridenabled applications.

This paper outlines issues that arose in two UK-wide initiatives which have deployed C \& IT in Higher and Further Education. The first initiative of interest was the Teaching and Learning Technologies Project (TLTP). This initiative has recently ended, after10 years of funding. The first phases of the TLTP consisted of 72 subject-specific projects, many of which produced multimedia resources. More recent projects focused on web-based delivery of these products, and other forms of networked education.

The second initiative, which has been promoted by JISC (the Joint Information Systems Committee), concerns the use of Learning Environments (LE). Within UK higher and further education there are now many users of web-based applications variously described as virtual 
learning environments (VLE) including First Class, WebCT and BlackBoard. Many institutions are also using locally developed VLE such as TAGS, COSE and Merlin [7], [8], [9]. More recently managed learning environments (MLE) - the integration of VLE with the institutions MIS - have been the main funding focus for JISC supported projects [10].

\section{IMPORTANT ISSUES}

An analysis of the above initiatives has identified the following issues as problematic for elearning [11], [10]:

- Cost

- Evaluation

- Sustainability

- Focus

- Standards

- Social Learning

- De-skilling

- Acceptance and take-up

Many of the above have implications for those who are intended to use the new educational technologies, namely the lecturers and teachers. The next section details the problems that were identified in the analysis of reports and papers generated by the initiatives.

\section{IMPACT OF E-LEARNING ISSUES}

\subsection{Cost}

The actual cost of networked learning is contentious. Many claim cost-benefits for e-learning. The main assumption is that there is no extra cost, or comparable costs, in using educational technology. This was expressed as the need to show efficiency gains during the TLTP period. There are those who claim that they know about the cost of developing C\&IT, but assumptions concerning economies of scale or time-scale of use adjust the true cost downwards [12]. It is unusual for infrastructure and maintenance costs (which are of great importance for e-learning service provision) to be explicitly included in cost-benefit analysis.

\subsection{Evaluation}

What is evaluated? There seems confusion over how to evaluate learning efficacy via educational technology. The focus of evaluation varies from usability issues, type of application, software functionality [13], 'soft' studies of student attitudes, and as suggested above, cost. There are few evaluations of the UK-wide impact of particular programmes for C\&IT [14], [10].

\subsection{Sustainability}

Sustainability has a persistent theme for the last 30 years of C\&IT in education, as it has for computing in general. Timeliness of adoption of new technologies by a community has a farreaching effect on sustainability: by the time a novel technology has been taken up in the wider educational community it is out of date. In addition the research efforts of those who test the particular technology are ignored as managers wish to use off-the-shelf commercial solutions. The paradox of research and development in educational technologies is that during the lifetime of the project there is already some other technology on the horizon which will supersede or replace the focus of the current enthusiasm. The replacement technologies often over-stretch the existing infrastructure requirements.

\subsection{Focus}

An important issue for the success of any IS project is focus. However, educational or pedagogic objectives are rarely discussed by those who drive initiatives. It is often the case that the originators of change promote the idea that a particular problem will be solved by the application of technology, even if there is no evidence for such an outcome. For example, in the UK the wider access agenda is often expected to be solved by e-learning, thereby ignoring the costs to the individual, and the high drop-out rates of distance learning. 


\subsection{Social Learning}

e-learning blurs the distinction between Distance Learning versus campus-based learning. There is an assumed equivalence of these models which needs to be carefully considered. Networked learning institutes are often given the name 'university' but are more akin to distance learning establishments such as the UK Open University than the majority of campus-based institutions. What are the implications for the teacher's role when such blurring occurs? How does this affect the role of the social in learning? [15], [16].

\subsection{The Threat of de-skilling}

Is the objective of e-learning the replacement of the educator? Threats to the educator's professionalism include unbundling and interoperability. The concept of unbundling follows the division of labour needs of Distance Learning discussed above. Patel and Franklin's report to JISC on MLE states:

"Unbundling the delivery of HE courses is a key issue in the provision of a national learning infrastructure. Currently the delivery of courses in HE is bundled i.e. the same people design develop and deliver courses and materials and deliver and conduct assessment and courses are studied as a whole at one institution." [17]

Thus the professional role of the lecturer or teacher in controlling their own materials is directly challenged by the impetus of networked learning.

There has also been, in the UK, an unpredicted growth of 'specialised' support - the Learning Technologist with as yet no formal or professional status within the sector. Some propose that learning technologists are vital to re-introduce the social learning aspects to e-learning [18]. What is the new role of the lecturer if learning technologists or e-moderators are required to make e-learning work?

\subsection{Standards}

In the case of web-based learning the need for interoperability of systems translates into a quest for meta-data or classification systems for educational content. Here content is talked about in terms of 'learning objects' or 'chunks' which may have wider application than a specific course and are seen as the key to material being created in one system and being transferable between different systems. There are still unresolved issues of quality and consistency associated with this view. In addition the management of learning is seen only in terms of the production of small enough 'chunks'. Unfortunately there is as yet no single definition of what constitutes a 'learning object'. Many vendors are creating their own definitions with little recourse to the diversity of practise among educators. Hence there are competing standards, some of which emerge from training in the US (e.g. SCORM, ADL). This also raises issues concerning cultural differences in education. There is already work to show that expectations of the way teachers use material have proved incorrect [19].

\subsection{Acceptance and Take-up}

By the end of the TLTP initiative it was discovered that very few products were in use. Those employed were generally for pre-university education - often used to bring students up to a particular level of achievement. The common consensus from those involved in the projects was that to increase use staff needed to be taught about C\&IT. The concept of possible replacement of staff by new technologies, and hence cost-benefits, were rejected. The technology was seen as an addition to range of techniques available for lecturers and teachers. This had an additional effect on take-up, also noted in the LE initiative. Lectures noted that this addition of technology increased the individual workload tremendously. In the case of production of content for LE this may seem so overwhelming, given that staff continue to teach with traditional methods, that they cannot easily include LE in their teaching practise.

\section{POSSIBLE REASONS FOR CONFLICT}

Those who are not educators, or enthusiasts for particular applications, tend to explain resistance to using C\&IT as being based on lack of staff-development or lack of management support for the champions of e-learning. Other explanations also include the claim that lecturers are scared of new technology. In fact, most lecturers in HE have assimilated computing 
technology as part of their everyday work - the production of overhead slides, the administration of student records, the use of e-mail for communicating with colleagues, students and research collaborators, the use of the Internet as an additional resource - all of these are common in UK academic life. What is difficult for those with involvement in research and development of novel educational technology to recognise, is that they may have ignored the diverse educational styles and objectives of professional staff, or that they may have designed unusable applications.

Another factor in the effective take-up of new technologies is that enthusiasm for C\&IT deployment in education produces a subsequent, often unrecognised, growth in IT infrastructure since all C\&IT is dependent on increased IT resources. This increases the influence that technologists have on the educational process, without engaging the educationalist.

In addition, Managerialism in e-learning manifests itself in ideas of cost-effectiveness; the replacement of the lecturer by technology; the introduction of the specialist technology moderator (the threat of de-skilling the educator); concepts of unbundling and granularity of content; the down-grading of pedagogy; assumptions of metadata classification by the nonspecialist; and the intervention of IT support and administration into teaching style (as in the MLE program). Can these types of conflict be avoided by possible future Grid technologies?

\section{CONCLUSION}

I would argue, in the light of these issues that in order to design effective Grid-based e-learning the current processes of education must be more fully understood. Educational objectives must be a focus for the design, as must the wishes and needs of the educators. The idea of radical change, brought about by new technologies, cannot be realised without understanding possible points of conflict such as those identified in previous initiatives.

\section{REFERENCES}

[1] ICT in Higher Education, \& February, 2003 1, 5. Times Higher Education Supplement.

[2] Kirschner, A. (2000) Fathom: the global university. LSE Magazine, Winter, London.

[3] Rosenfield, A. (2000) unxt.com (founder, chairman and CEO of unxt.com), LSE magazine, Winter, London.

[4] Ryan, Y. (2002) Emerging indicators of success and failure in borderless higher education, Report for The Observatory on Borderless Education, The Association for Commonwealth Universities. http://www.obhe.ac.uk/products/reports/pdf/February2002.pdf (6/04/02)

[5] Keen, P. G. W. (1981) Information Systems and Organizational Change. Communications of the ACM (CACM), 24, 1, 24-33.

[6] Beynon-Davies, P. (1999) Human error and information systems failure: the case of the London ambulance service computer-aided despatch system project. Interacting with Computers, 11, 699 - 720.

[7] Allison, C., Bain, A., McKechan, D., Michaelson, R. (2000) "Using TAGS for Distributed IT Project Management" in Proceedings of the LTSN-ICS 1st Annual Conference, Heriot-Watt University, Edinburgh, 23 - 25 August.

[8] COSE (2001) http://cetis.bangor.ac.uk/co3/cose.html

[9] Merlin (1999) http://www.hull.ac.uk/merlin

[10] Michaelson, R. (2002) Let's get real: Virtual or Managed Learning Environments, LTSNBest $2^{\text {nd }}$ Conference for Business, Management and Accounting, Edinburgh, April 2002.

[11] Michaelson, R. (2001) Learning from our mistakes: 10 years of UK-wide C\&IT initiatives, BAA Accounting Education SIG, Glamorgan.

[12] Bacsich, P., Ash, C., Boniwell, K., Kaplan, L., Mardell, J., Cavan-Atack, A. (1999) The cost of networked learning. A report for JCALT. Sheffield Hallam University, JISC. October.

[13] Britain, S. \& Liber O. (1999) A Framework for Pedagogical Evaluation of Virtual Learning Environments. JTAP Report, October. www.jtap.ac.uk/reports/htm/jtap-041.html (26/03/01).

[14] Selwyn, N. (2000). Researching computers and education - glimpses of the wider picture. Computers and Education, 34 (2000), 93-101.

[15] Peters, O. (1989) "The iceberg has not melted: further reflections on the concept of industrialisation and distance teaching". Open Learning, 4, 3, 3-8. Harlow: Longman Group.

[16] Brown, J. S., Duguid, P. (2002) The Social Life of Information, Harvard Business School Press. 
[17] Patel, D., Franklin, T. (2001) Summary Briefing Paper on issues for the development and implementation of MLE, JISC Report, 4 June 2001.

http://www.jisc.ac.uk/mle/reps/paper-1.htm

[18] Salmon, G. (2000) E-moderating: the key to teaching and learning online, Kogan-Page.

[19] Monthienvichienchai, R., Sasse, A., Wheeldon, R. (2001) Educational Metadata: Teacher's Friend or Foe? in Euro CSCL 2001, the proceedings of European Perspectives on Computersupported Collaborative Learning. Dillenbourg, P., Eurelings, A., Hakkarainen, K., eds. March 22-24, University of Maastricht, 508-519. 